\title{
Genetic diversity assessment using RAPD primers in insecticide resistant populations of diamondback moth Plutella xylostella (Linn.)
}

\author{
V. Sunitha ${ }^{1 *}$, T.V. K. Singh ${ }^{1}$, V. Ramesh Babu ${ }^{2}$ and J. Satyanarayana ${ }^{3}$ \\ ${ }^{1}$ Dean of Agriculture, Professor Jayashankar Telangana State Agricultural University (PJTSAU), Rajendranagar, \\ Hyderabad-500030 (Telangana), INDIA \\ ${ }^{2}$ Crop Protection Division, Central Research Institute for Jute and Allied Fibers, Barrackpore, Kolkata-700120 \\ (West Bengal), INDIA \\ ${ }^{3}$ Department of Entomology, College of Agriculture, PJTSAU, Rajendranagar, Hyderabad-500030 (Telangana), \\ INDIA \\ *Corresponding author. E-mail: vanamsunitha10@gmail.com \\ Received: December 3, 2014; Revised received: March 18, 2015; Accepted: April 7, 2015
}

\begin{abstract}
Genetic diversity in acephate, spinosad and Cry2Ab resistant Plutella xylostella collected from three states of India was assessed by RAPD markers. The DNA extracted from larvae was subjected to polymerase chain reaction using 10 RAPD primers. The highest number alleles (7) were produced by primer ABA-13, followed by six alleles each by primers ABA-2, 7, 8, 11, 14; five alleles each were produced by ABA-4, 9, 10, 12. UPGMA analysis clustered the acephate, spinosad and Cry2Ab treated P.xylostella populations into two groups with overall similarity level of $33 \%, 27 \%$ and $34 \%$ respectively. Cluster A consisted 11 samples while Cluster B consisted only $F_{1}$ of acephate and spinosad treated Karnataka population. In Cry2Ab treated population Cluster B comprised 11 samples and Cluster $A$ had out grouped singly i.e. $F_{0}$ generation from Karnataka. The genetic variability between the acephate, spinosad and Cry2Ab treated populations ranged from 33 to $69 \%, 27$ to $56 \%$ and 34 to $69 \%$ respectively. Acephate and spinosad treated $F_{1}$ population and Cry2Ab treated $F_{0}$ population from Karnataka were out grouped from rest of the populations.
\end{abstract}

Keywords: Acephate, Cry2Ab, Molecular characterization, Plutella xylostella, RAPD markers,

\section{INTRODUCTION}

Diamondback moth (DBM), Plutella xylostella (L.) (Lepidoptera: Yponomeutidae), is an important pest of cruciferous crops and enjoys worldwide distribution (CIE, 1967) inflicting huge crop losses each year. Looking at its versatility in rapidly evolving resistance to almost all classes of insecticides and there must be a strong genetic basis governing the behaviour of $P$. xylostella in making it a serious pest on cruciferous crops. Thus, the understanding of genetic variation of insecticide resistant strains of $P$. xylostella within and between geographical regions will help in managing this insect. The high degree of migration, indiscriminate pesticide application by farmers and innate ability of the insect to quickly develop resistance to applied insecticides have been considered as factors responsible for this pest to attain the status of key pest (Sivapragasam et al. 1996, Ferre and Van Rie 2002).

However, the possibility of differential susceptibility status in $P$. xylostella due to widespread mixing of population through migration, a common feature in this insect (Tang et al., 2006), cannot be over ruled. Molecular markers are ideal choices for studying genetic differences among individuals of different regions. The allelic differences identified from randomly amplified polymorphic DNA (RAPD) can be used to estimate the extent of genetic differences, gene flow pattern within and between populations (Silva et al., 2000). RAPD method relies on the use of short, random DNA primers to amplify genomic DNA between adjacent sites complimentary to the primer(s) and thus providing a sample of widely distributed sites on the genome for marking studies (Tay et al., 2008). RAPD analysis based on PCR is useful in population genetic studies of many insect species (Zhou et al., 2000). Though PCR -RAPD analysis is protocol-sensitive, it is simple to practice and reliable for repeatable banding pattern once identified (Belaj et al., 2003). Therefore, the present study was taken up to quantify the potential of development of resistance to acephate, spinosad and Cry $2 \mathrm{Ab}$ and to generate the molecular association of resistance pattern in acephate, spinosad and Cry2Ab resistant P. xylostella using randomly amplified polymorphic DNA (RAPD) primers occurring on different regions of India.

\section{MATERIALS AND METHODS}

Insect strains: Experiments for the genetic diversity in $P$. xylostella from three regions of India were conducted at the Molecular Laboratory, Entomology Division, 
Central Institute of Cotton Research (CICR), Nagpur. $P$. xylostella larvae were collected from Andhra Pradesh, Karnataka and Delhi regions. All the three populations of Diamondback Moth (DBM) were reared under room temperature and the third instar larvae of $\mathrm{F}_{0}$ generation were subjected to the calculated LC 50 values of the acephate, spinosad and Cry2Ab. The progeny of the first surviving lot was termed as the $F_{1}$ generation $\left(F_{1}\right)$. The third instar larvae of $F_{1}$ generation were subjected to different concentrations of the acephate, spinosad and Cry2 $\mathrm{Ab}$ and the survivals at the $80.00 \%$ mortality were reared to next generation $\left(\mathrm{F}_{2}\right)$ and thus exposures continued upto three generations. Thus, all three populations were subjected to selection pressure at the concentration giving $80.00 \%$ mortality of acephate, spinosad and Cry $2 \mathrm{Ab}$ and thus the selection was continued up to three generations. From the survivals obtained in each generation, sufficient larvae were reared to the next generation and 4-5 larvae were stored in plastic screw cap tubes containing $100 \%$ alcohol for molecular characterization work.

DNA extraction: Genomic DNA was extracted from the larvae of $P$. xylostella using SDS- PAGE method (Miller et al., 1988). Larvae used for DNA isolation were well grounded in $200 \mu \mathrm{l}$ of ice cold homogenization buffer using plastic homogenizer in autoclaved $2 \mathrm{ml}$ eppendorf tube. After grinding the larvae then $100 \mu \mathrm{l}$ of lysis buffer was added and kept for 5-10 minutes at room temperature after thorough mixing. The mixture was incubated at $65^{\circ} \mathrm{C}$ in a water bath for 30 minutes with a constant shaking at every 10 minutes interval and was further incubated. $30 \mu \mathrm{l}$ of potassium acetate was added to tubes and was incubated at $4^{\circ} \mathrm{C}$ for $30 \mathrm{~min}$ utes and centrifuged at 12,000 rpm for 10 minutes at $4^{\circ} \mathrm{C}$ temperature. The aqueous phase was transferred to a new eppendorf tube with broad tip and $300 \mu \mathrm{l}$ of chilled 100 per cent ethanol was added.

The tubes were left overnight at $-20^{\circ} \mathrm{C}$, and at the end of the period the tubes were centrifuged at $12,000 \mathrm{rpm}$ for 20 minutes at $4^{0} \mathrm{C}$ temperature. The liquid phase was decanted and pellet was washed with $70 \%$ ice cold ethanol and the tubes were spun at 12,000 rpm for ten minutes at $4^{\circ} \mathrm{C}$ temperature. The liquid phase was again decanted and the pellet was kept in vacuum drier for 10-15 minutes to remove the minor droplets of alcohol. The pellet of DNA was dissolved in $50 \mu \mathrm{l}$ of TE (Tris- EDTA) buffer (pH- 8) and transferred to a $1 \mathrm{ml}$ eppendorf tube and stored at $-20^{\circ} \mathrm{C}$.

DNA purification: The isolated DNA pellet obtained was mixed with $100 \mu 1 \mathrm{TE}$ buffer, $5 \mu \mathrm{l}$ RNAse (1mg/ $\mathrm{ml}$ ) and was incubated at $37^{\circ} \mathrm{C}$ for one hour. An equal volume of chloroform and iso-amyl alcohol (24:1 v/v) was added to the eppendorf tube and mixed by gentle swirling for 15 minutes at $25^{\circ} \mathrm{C}$ in centrifuge. The above procedure was repeated once or twice in case of necessity to purify DNA. The part of DNA sample was diluted with appropriate amount of sterilized distilled water to a working concentration of $25 \mathrm{ng} / \mu \mathrm{l}$ and stored at $-20^{\circ} \mathrm{C}$. The intact genomic DNA was visualized in a $0.8 \%$ agarose gel and quantified using a gel electrophoresis following standard procedures. Depending upon the concentration, the DNA samples were diluted with sterile water to get a working solution of $20-25 \mathrm{ng} / \mu \mathrm{l}$.

Primers used for the RAPD analysis: Ten primers of ABA- 2 to 14 series (Table 1) were used to amplify genomic DNA of survivals of different generations $\left(\mathrm{F}_{0}\right.$ to $\mathrm{F}_{3}$ ) of $P$. xylostella from three regions. Out of these, those giving satisfactory number of amplification bands were chosen for the study. Polymerase Chain Reaction (PCR) amplification was carried out with 25-50 ng of genomic DNA, $1.5 \mathrm{mM} \mathrm{Mgcl}_{2}, 0.9 \mathrm{U}$ Taq DNA Polymerase, $10 \mathrm{x}$ buffer, 5 pico mole primer and $100 \mathrm{mM}$ of each dNTPs. The volume was made upto $25 \mu \mathrm{l}$ with sterile distilled water. PCR tubes containing the above components were capped and given a pulse spin to allow proper setting of the reaction mixture. PCR was carried out in Master Cycler Eppendorf system. Electrophoresis was carried out at $70 \mathrm{~V}$ for 3-4 hours. The resolved amplification products were visualized under UV light at $302 \mathrm{~nm}$ wave length in gel documentation system (Alpha Innotech Corporation). The illuminated gel was photographed.

Scoring of bands and statistical analysis: Based on log molecular weight of the co-migrating 100 bp DNA marker and their migration distances, scatter plots were established and trend lines with best fit were fitted. Based on the mathematical expression of the trend lines the molecular weight of the fragment corresponding to their migration distances was calculated. The individual DNA bands were scored as present or absent (1/0) in the amplification profile of each sample. Only clear bands with good resolution were scored.

All the information/results obtained from the above were subjected to UPGMA (Unweighted pair group method with arithmetic average) in NTSYS Pc 2 Software package (Fakruddin et al., 2004). Standard statistical procedures to obtain relationships among different populations from different regions and the relationship between the individuals of same population corresponding to acephate, spinosad and Cry $2 \mathrm{Ab}$ dendrograms were obtained from the banding patterns obtained in the study.

\section{RESULTS AND DISCUSSION}

In all the three populations, the primer $\mathrm{ABA}-13$ generated a maximum number of seven alleles, whereas, ABA-4, 9, 10, 12 generated five alleles each, whereas, 6 alleles individually were generated in ABA-2, 7, 8, 11, and ABA -14 primers (Table 2).

RAPD profiling of acephate, spinosad and Cry2Ab treated strains: Both polymorphic, monomorphic amplicons were produced by all the primers. Majority of the amplicons are categorized to be polymorphic.

Acephate: Primer ABA -02 produced an amplicon of $750 \mathrm{bp}$ that was specific to untreated population in all 
Table 1. RAPD primer names along with their sequences.

\begin{tabular}{ccc}
\hline S. $\mathbf{N}$. & Primer name & Primer sequence \\
\hline 1 & ABA-02 & TGCCGAGCTG \\
2 & ABA-04 & AATCGGGCTG \\
3 & ABA-07 & GAAACGGGTG \\
4 & ABA-08 & GTGACGGGTG \\
5 & ABA-09 & GGGTAACGCC \\
6 & ABA-10 & GTGATCGCAG \\
7 & ABA-11 & CAATCGCCGT \\
8 & ABA-12 & TCGGCGATAG \\
9 & ABA-13 & CAGCACCCAC \\
10 & ABA-14 & TCTGTGCTGG \\
\hline
\end{tabular}

the three generations and was absent in insecticide (acephate) treated strains from Andhra Pradesh population. The amplicon was specific only to Andhra Pradesh population, and was not present either in Karnataka or Delhi population. The presence of this $750 \mathrm{bp}$ amplicon in all the generations of untreated strains from Andhra Pradesh suggests that RAPD marker ABA-02 might be linked to flanking regions of a gene responsible for susceptibility of $P$. xylostella to acephate.

Primer ABA-04 generated an 800 bp amplicon in acephate resistant strain of Andhra Pradesh population whereas, primer ABA-12 produced a 820 bp amplicon in acephate treated population of Delhi (Plate1). These amplicons were absent in their corresponding untreated control strains. This reveals that the RAPD marker ABA-04 and ABA-12 might be linked to the flanking region of a gene responsible for acephate resistance in P. xylostella strains from Andhra Pradesh and Delhi respectively.

Spinosad: Similar to acephate treated strains of Andhra Pradesh, primer ABA-04 ought generated a specific
Table 2. Polymorphic information of RAPD markers of

\begin{tabular}{lcccc}
\hline $\begin{array}{l}\text { Marker } \\
\text { name }\end{array}$ & $\begin{array}{l}\text { No. of } \\
\text { Alleles }\end{array}$ & $\begin{array}{c}\text { Polymorphic alleles } \\
\text { Andhra } \\
\text { Pradesh }\end{array}$ & Karnataka & Delhi \\
\hline ABA-02 & 6 & 51 & 97 & 66 \\
ABA-04 & 5 & 70 & 86 & 42 \\
ABA-07 & 6 & 93 & 77 & 66 \\
ABA-08 & 6 & 86 & 106 & 77 \\
ABA-09 & 5 & 61 & 71 & 59 \\
ABA-10 & 5 & 62 & 65 & 54 \\
ABA-11 & 6 & 75 & 76 & 87 \\
ABA-12 & 5 & 39 & 57 & 34 \\
ABA-13 & 7 & 85 & 72 & 80 \\
ABA-14 & 6 & 33 & 54 & 61 \\
\hline
\end{tabular}

amplicon of 800bp (Plate 2.) in spinosad treated survivals from $F_{0}, F_{1}, F_{2}, F_{3}$ of Andhra Pradesh resistant strain and the amplicon was wanting in control population, revealing that $800 \mathrm{bp}$ amplicon in ABA-04 primer might be linked to the flanking region of a gene responsible for spinosad resistance in $P$. xylostella strains from Andhra Pradesh.

Cry2Ab: Likewise in acephate treated resistant strains of Andhra Pradesh, primer ABA-02 did generated an $750 \mathrm{bp}$ amplicon in the untreated control Andhra Pradesh population, and was wanting in Cry2Ab treated survivals from $\mathrm{F}_{0}$ to $\mathrm{F}_{3}$ generations and this innate amplicon might be linked to flanking regions of a gene responsible for susceptibility of $P$. xylostella to Cry2Ab. Similarly primer ABA-12 generated a 820 bp amplicon in Cry2Ab treated survivals of Delhi population, and was lacking in control population revealing that presence of $\mathrm{Cry} 2 \mathrm{Ab}$ resistance gene in the flanking region was might be the reason for developing resistance against Cry2Ab toxin in Delhi population.

Genetic diversity analysis of acephate, spinosad and Cry2Ab resistant $P$. xylostella strains :The coeffi-

Table 3. Inter and intra cluster distances of three populations of DBM against acephate.

\begin{tabular}{|c|c|c|c|c|c|c|c|c|c|c|c|c|}
\hline & $\mathbf{F}_{0} \mathbf{K N}$ & $\mathbf{F}_{1} \mathbf{K N}$ & $\mathbf{F}_{2} \mathbf{K N}$ & $\mathbf{F}_{3} \mathbf{K N}$ & $F_{0} D$ & $F_{1} D$ & $F_{2} \mathbf{D}$ & $F_{3} \mathbf{D}$ & $\mathbf{F}_{0} \mathbf{A P}$ & $\begin{array}{c}\mathbf{F}_{1} \\
\mathbf{A P}\end{array}$ & $\begin{array}{c}\mathbf{F}_{2} \\
\mathbf{A P}\end{array}$ & $\begin{array}{r}\mathbf{F}_{3} \\
\mathbf{A P}\end{array}$ \\
\hline $\mathrm{F}_{0} \mathrm{KN}$ & 1.00 & & & & & & & & & & & \\
\hline $\mathrm{F}_{1} \mathrm{KN}$ & 0.37 & 1.00 & & & & & & & & & & \\
\hline $\mathrm{F}_{2} \mathrm{KN}$ & 0.40 & 0.27 & 1.00 & & & & & & & & & \\
\hline $\mathrm{F}_{3} \mathrm{KN}$ & 0.56 & 0.28 & 0.50 & 1.00 & & & & & & & & \\
\hline $\mathrm{F}_{0} \mathbf{D}$ & 0.51 & 0.31 & 0.40 & 0.60 & 1.00 & & & & & & & \\
\hline $\mathbf{F}_{1} \mathbf{D}$ & 0.49 & 0.29 & 0.48 & 0.54 & 0.58 & 1.00 & & & & & & \\
\hline$F_{2} \mathbf{D}$ & 0.37 & 0.28 & 0.37 & 0.46 & 0.57 & 0.68 & 1.00 & & & & & \\
\hline$F_{3} \mathbf{D}$ & 0.40 & 0.37 & 0.41 & 0.38 & 0.48 & 0.50 & 0.52 & 1.00 & & & & \\
\hline $\mathbf{F}_{0} \mathbf{A P}$ & 0.48 & 0.30 & 0.41 & 0.44 & 0.55 & 0.67 & 0.48 & 0.50 & 1.00 & & & \\
\hline $\mathbf{F}_{1} \mathbf{A P}$ & 0.35 & 0.31 & 0.35 & 0.39 & 0.54 & 0.55 & 0.47 & 0.45 & 0.60 & 1.00 & & \\
\hline $\mathbf{F}_{2} \mathbf{A P}$ & 0.45 & 0.35 & 0.44 & 0.30 & 0.41 & 0.36 & 0.27 & 0.39 & 0.42 & 0.44 & 1.00 & \\
\hline $\mathbf{F}_{3} \mathbf{A P}$ & 0.48 & 0.40 & 0.47 & 0.46 & 0.60 & 0.55 & 0.54 & 0.52 & 0.59 & 0.54 & 0.52 & 1.00 \\
\hline
\end{tabular}

AP- Andhra Pradesh; KN- Karnataka; D- Delhi; $F_{0}, F_{1}, F_{2}, F_{3}$ generations 
Table 4. Inter and intra cluster distances of three populations of DBM against spinosad.

\begin{tabular}{|c|c|c|c|c|c|c|c|c|c|c|c|c|}
\hline & $\begin{array}{c}\mathbf{F}_{\mathbf{0}} \\
\mathbf{K N}\end{array}$ & $\begin{array}{c}\mathbf{F}_{1} \\
\mathbf{K N}\end{array}$ & $\begin{array}{c}\mathbf{F}_{2} \\
\mathrm{KN}\end{array}$ & $\begin{array}{c}\mathbf{F}_{\mathbf{3}} \\
\mathbf{K N}\end{array}$ & $F_{0} D$ & $\mathbf{F}_{1} \mathbf{D}$ & $F_{2} \mathbf{D}$ & $F_{3} \mathbf{D}$ & $\mathbf{F}_{0} \mathbf{A P}$ & $\mathbf{F}_{1} \mathbf{A P}$ & $\mathbf{F}_{2} \mathbf{A P}$ & $\mathbf{F}_{3} \mathbf{A P}$ \\
\hline $\mathrm{F}_{0} \mathrm{KN}$ & 1.00 & & & & & & & & & & & \\
\hline $\mathrm{F}_{1} \mathrm{KN}$ & 0.20 & 1.00 & & & & & & & & & & \\
\hline $\mathrm{F}_{2} \mathrm{KN}$ & 0.33 & 0.28 & 1.00 & & & & & & & & & \\
\hline $\mathrm{F}_{3} \mathrm{KN}$ & 0.28 & 0.25 & 0.28 & 1.00 & & & & & & & & \\
\hline $\mathrm{F}_{0} \mathrm{D}$ & 0.35 & 0.17 & 0.25 & 0.30 & 1.00 & & & & & & & \\
\hline $\mathrm{F}_{1} \mathrm{D}$ & 0.50 & 0.23 & 0.30 & 0.29 & 0.50 & 1.00 & & & & & & \\
\hline $\mathrm{F}_{2} \mathrm{D}$ & 0.38 & 0.29 & 0.30 & 0.21 & 0.35 & 0.31 & 1.00 & & & & & \\
\hline $\mathrm{F}_{3} \mathrm{D}$ & 0.37 & 0.26 & 0.34 & 0.33 & 0.44 & 0.54 & 0.41 & 1.00 & & & & \\
\hline $\mathrm{F}_{0} \mathrm{AP}$ & 0.40 & 0.25 & 0.40 & 0.32 & 0.40 & 0.41 & 0.44 & 0.55 & 1.00 & & & \\
\hline $\mathrm{F}_{1} \mathrm{AP}$ & 0.41 & 0.32 & 0.17 & 0.20 & 0.35 & 0.39 & 0.42 & 0.34 & 0.43 & 1.00 & & \\
\hline $\mathrm{F}_{2} \mathrm{AP}$ & 0.43 & 0.39 & 0.26 & 0.27 & 0.31 & 0.47 & 0.36 & 0.42 & 0.45 & 0.51 & 1.00 & \\
\hline $\mathrm{F}_{3} \mathrm{AP}$ & 0.34 & 0.29 & 0.38 & 0.29 & 0.29 & 0.25 & 0.31 & 0.31 & 0.30 & 0.34 & 0.36 & 1.00 \\
\hline
\end{tabular}

AP- Andhra Pradesh; KN- Karnataka; D- Delhi; $F_{0}, F_{1}, F_{2}, F_{3}$ generat

Table 5. Inter and intra cluster distances of three populations of DBM against Cry2Ab.

\begin{tabular}{|c|c|c|c|c|c|c|c|c|c|c|c|c|}
\hline & $\begin{array}{c}\mathbf{F}_{\mathbf{0}} \\
\mathbf{K N}\end{array}$ & $\begin{array}{c}\mathbf{F}_{1} \\
\mathbf{K N}\end{array}$ & $\begin{array}{c}\mathbf{F}_{2} \\
\mathbf{K N}\end{array}$ & $\mathbf{F}_{3} \mathbf{K N}$ & $F_{0} D$ & $F_{1} \mathbf{D}$ & $F_{2} \mathbf{D}$ & $F_{3} \mathbf{D}$ & $\begin{array}{c}\mathbf{F}_{0} \\
\mathbf{A P}\end{array}$ & $\begin{array}{c}\mathbf{F}_{1} \\
\mathbf{A P}\end{array}$ & $\begin{array}{c}\mathbf{F}_{2} \\
\mathbf{A P}\end{array}$ & $\begin{array}{r}\mathbf{F}_{3} \\
\mathbf{A P}\end{array}$ \\
\hline $\mathrm{F}_{0} \mathrm{KN}$ & 1.00 & & & & & & & & & & & \\
\hline $\mathrm{F}_{1} \mathrm{KN}$ & 0.35 & 1.00 & & & & & & & & & & \\
\hline $\mathrm{F}_{2} \mathrm{KN}$ & 0.43 & 0.48 & 1.00 & & & & & & & & & \\
\hline $\mathrm{F}_{3} \mathrm{KN}$ & 0.29 & 0.25 & 0.37 & 1.00 & & & & & & & & \\
\hline $\mathrm{F}_{0} \mathrm{D}$ & 0.38 & 0.43 & 0.64 & 0.36 & 1.00 & & & & & & & \\
\hline $\mathrm{F}_{1} \mathrm{D}$ & 0.35 & 0.40 & 0.51 & 0.35 & 0.68 & 1.00 & & & & & & \\
\hline $\mathrm{F}_{2} \mathrm{D}$ & 0.35 & 0.40 & 0.58 & 0.41 & 0.55 & 0.65 & 1.00 & & & & & \\
\hline $\mathrm{F}_{3} \mathrm{D}$ & 0.31 & 0.40 & 0.46 & 0.38 & 0.64 & 0.69 & 0.54 & 1.0 & & & & \\
\hline $\mathrm{F}_{0} \mathrm{AP}$ & 0.36 & 0.30 & 0.57 & 0.37 & 0.68 & 0.65 & 0.58 & 0.53 & 1.00 & & & \\
\hline $\mathrm{F}_{1} \mathrm{AP}$ & 0.20 & 0.26 & 0.38 & 0.30 & 0.36 & 0.39 & 0.39 & 0.35 & 0.38 & 1.00 & & \\
\hline $\mathrm{F}_{2} \mathrm{AP}$ & 0.24 & 0.30 & 0.41 & 0.30 & 0.45 & 0.52 & 0.45 & 0.42 & 0.44 & 0.53 & 1.00 & \\
\hline $\mathrm{F}_{3} \mathrm{AP}$ & 0.38 & 0.34 & 0.56 & 0.38 & 0.54 & 0.51 & 0.47 & 0.48 & 0.50 & 0.43 & 0.58 & 1.00 \\
\hline
\end{tabular}

AP- Andhra Pradesh; KN- Karnataka; D- Delhi; $\mathrm{F}_{0}, \mathrm{~F}_{1}, \mathrm{~F}_{2}, \mathrm{~F}_{3}$ generations

cients of variations generated groups in UPGMA analysis for all the survivals treated with acephate, spinosad and Cry $2 \mathrm{Ab}$ from $\mathrm{F}_{0}$ to $\mathrm{F}_{3}$ generation of three populations are presented in Tables 3, 4 and 5 .

Acephate: Among twelve test samples of acephate resistant strains maximum similarity of $68 \%$ was observed between $F_{1}$ generation and $F_{2}$ generation of Delhi strain and minimum similarity $27 \%$ was observed between $F_{1}$ and $F_{2}$ of Karnataka strains.

Dendrogram based on similarity matrix generated from UPGMA analysis segregated the strains into two groups, A and B with a common genetic distance of 0.33, while group B out grouped separately (Fig.1). Group A consisted 11 samples including $F_{0}, F_{2}, F_{3}$ generations of Karnataka, $F_{0}, F_{1}, F_{2}, F_{3}$ and all generations of Delhi and Andhra Pradesh strains with an overall similarity level of $42 \%$. (The overall genetic similarity between the three populations treated with acephate was 33 to $69 \%$ ). Despite the different geographic locations $\mathrm{F}_{0}$ generation of Delhi, $\mathrm{F}_{3}$ Andhra Pradesh and $\mathrm{F}_{2}$ generation of Karnataka and Andhra Pradesh were grouped together suggesting that the ancestral generations of these might have shown variable patterns of migration among themselves.

Spinosad: Among the twelve test samples of spinosad resistant strains, the maximum similarity of $55 \%$ was observed between $\mathrm{F}_{3}$ generation of Delhi and $\mathrm{F}_{0}$ generation of Andhra Pradesh population while minimum similarity $17 \%$ was observed among $\mathrm{F}_{2}$ generation of Karnataka and $F_{1}$ generation of Andhra Pradesh population and also in $\mathrm{F}_{1}$ generation of Karnataka and $\mathrm{F}_{0}$ generation of Delhi (Table 4).

Dendrogram, based on similarity matrix generated from UPGMA analysis segregatedthe samples two main groups i.e. $\mathrm{A}$ and $\mathrm{B}$ with a common genetic distance of 0.27 (Fig. 2). The group $A$ included 11 samples $\left(\mathrm{F}_{0}, \mathrm{~F}_{2}, \mathrm{~F}_{3}\right.$ generations of Karnataka, $\mathrm{F}_{0}, \mathrm{~F}_{1}, \mathrm{~F}_{2}$, $\mathrm{F}_{3}$ generations of Delhi and Andhra Pradesh population) with a overall similarity level of $28 \%$ and was divided into two sub-groups. Group $B$ with $F_{1}$ generation of Karnataka population out-grouped singly.The overall genetic similarity between the three populations treated with spinosad was 27 to $56 \%$.

Cry2Ab: Maximum similarity of $69 \%$ was found between $\mathrm{F}_{1}$ and $\mathrm{F}_{3}$ generations of Delhi population while minimum similarity of $20 \%$ was observed between $F_{1}$ 


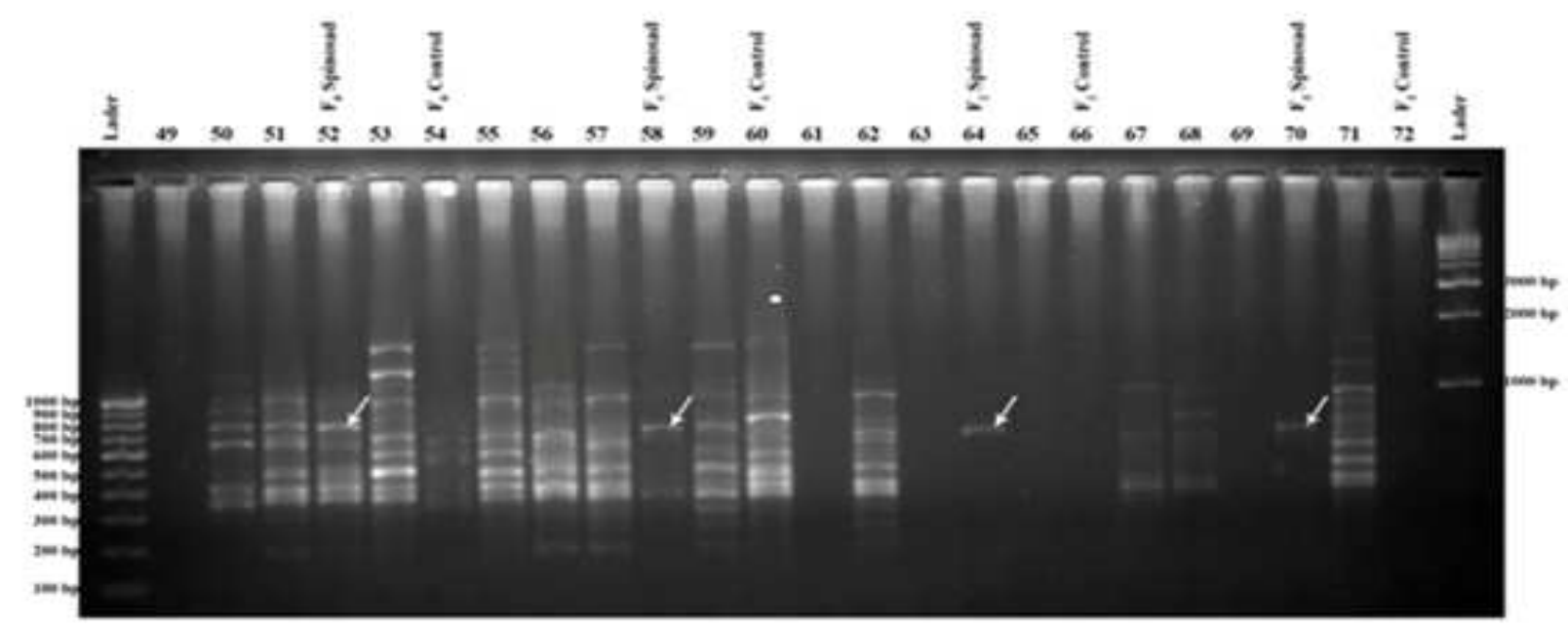

Plate 1. DNA profile of Diamondback moth larvae survivals and controls of acephate treatment from primer ABA-12 (820bp) of Delhi population.

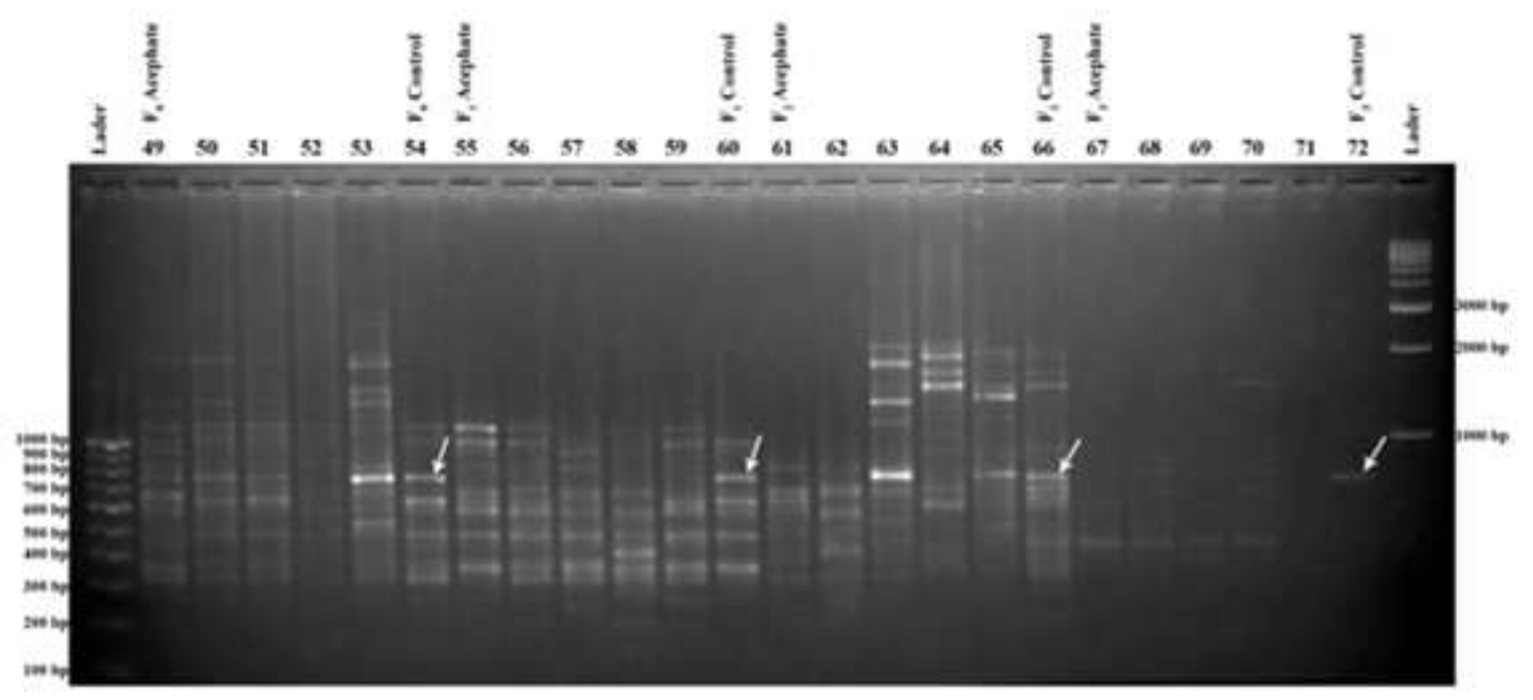

Plate 2. DNA profile of Diamondback moth larvae survivals and controls of spinosad treatment from primer ABA-04 (800bp) of Andhra Pradesh population.

generation of Andhra Pradesh and $\mathrm{F}_{0}$ generation of Karnataka population. The genetic relatedness between the three populations treated with Cry2Ab was 20 to $69 \%$ (Table 5).

Dendrogram, based on similarity matrix generated from UPGMA analysis segregated the twelve test samples of Cry2Ab treated DBM populations into two major groups, group A and group B, which shared a common genetic distance 0.34 . Group A consisting of $\mathrm{F}_{0}$ generation of Karnataka outstretched as a separate group while group $B$ included 11 samples $\left(F_{0}, F_{2}, F_{3}\right.$ generations of Karnataka, $F_{0}, F_{1}, F_{2}, F_{3}$ generations of Delhi and Andhra Pradesh population) (Fig.3).Overall similarity coefficient ranged between 34 to $69 \%$.

In the present study, acephate, spinosad and Cry $2 \mathrm{Ab}$ toxin treated $P$. xylostella populations showed overall, similarity coefficient ranging of 0.30 to 0.70 . These results depicted the formation of groups by and large based on the geographic locations and their proximity except for some of the insecticide treated strains. Although the populations (after selection pressure regarded as resistant strains) collected from different geographical locations some of the strains were grouped together. This suggests that the selection pressure of the insecticide with same concentrations might have responsible for the peculiar behavior of the strain exhibiting the genetic relatedness of the different populations. High gene flow between the populations as a result of intensive selection pressure cannot be over ruled for perpetuation of particular insect strain to survive. It also concluded that genetic diversity is also lowered by the extensive use of insecticides. Similarity may be due to large scale migration and inbreeding of DBM resulting in larger genetic dilution and low 


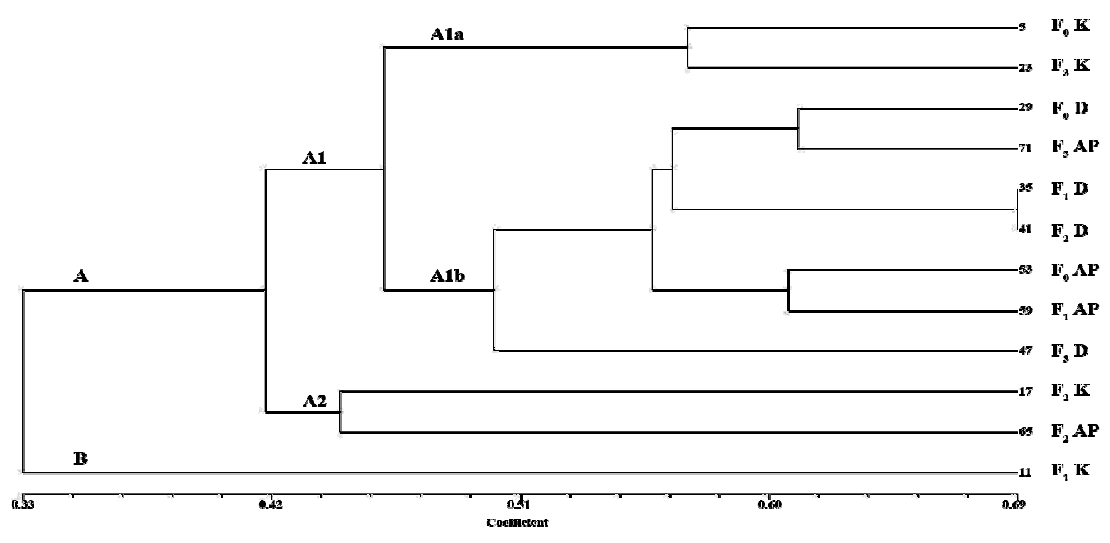

Fig. 1. Dendrogram showing diversity of Plutella xylostella of three populations with RAPDmarkers against acephate.

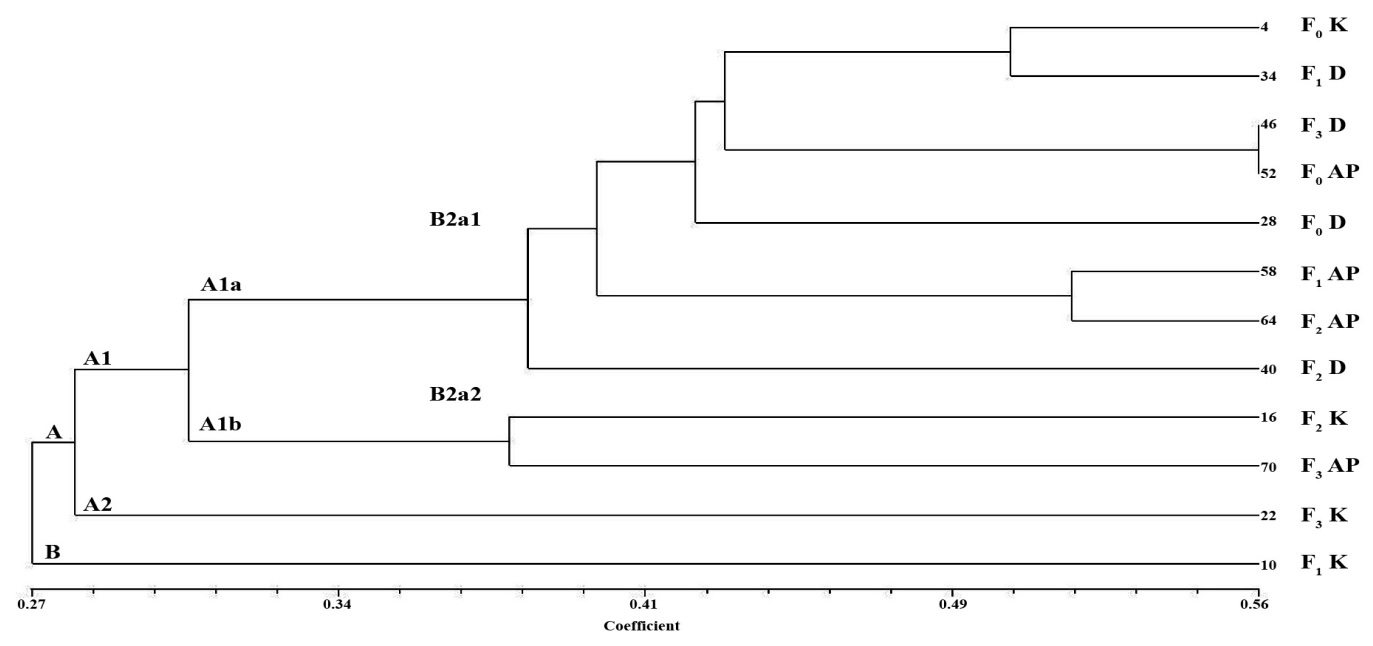

Fig. 2. Dendrogram showing diversity of Plutella xylostella of three populations with RAPD markers against spinosad.

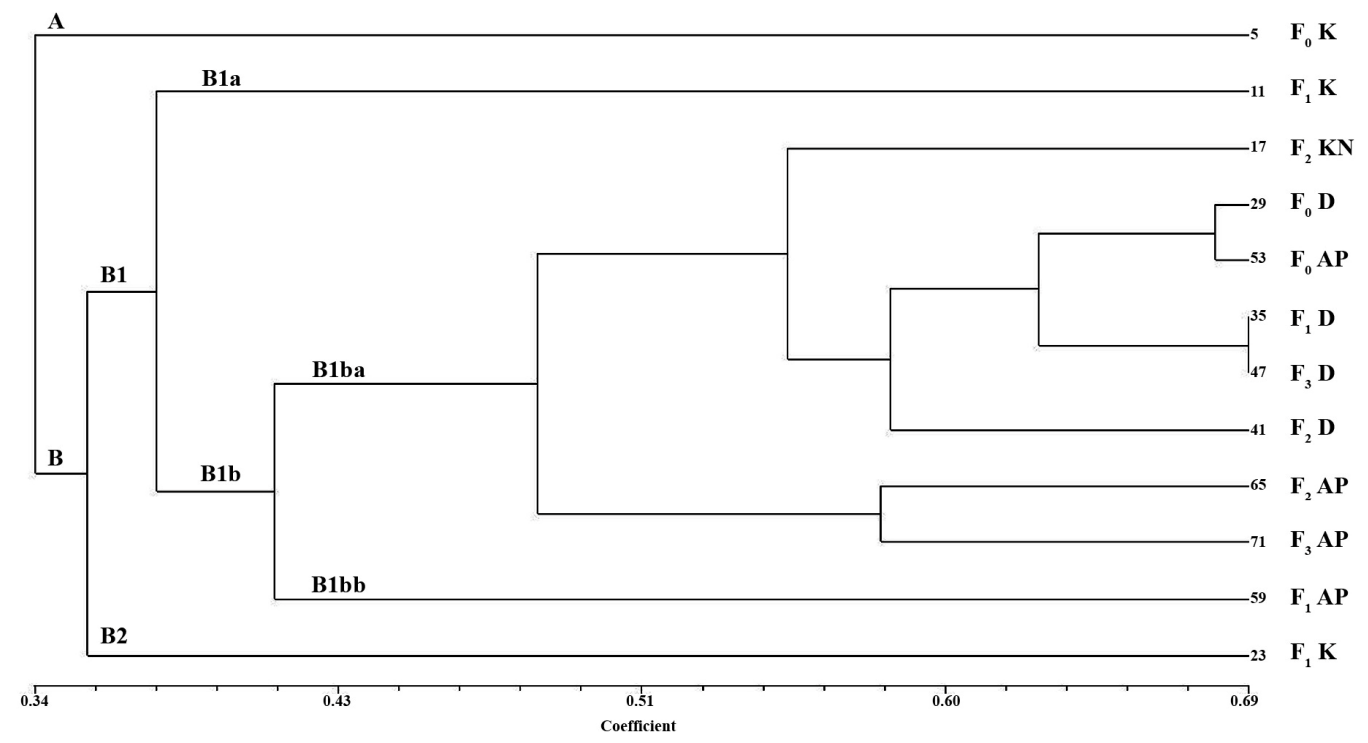

Fig. 3. Dendrogram showing diversity of Plutella xylostella of three populations with RAPD markers against Cry2Ab. 
genetic differentiation. Zhou et al. 2000 revealed that the RAPD analysis of Turkish and Israeli populations of Helicoverpa armigera shown low levels of genetic distance suggesting high genetic flow which is in line with the present study. Local selection pressures and barriers could provide for genetic isolation resulting in a high degree of genetic drift (Krumm et al., 2008).

Presence/absence of topological barriers due to weather / environmental factors and temporal barriers due to cropping pattern may play a key role in either high or low amount of genetic variability among geographical populations. Diamondback moth being migrative in nature would result in high genetic variability within a population, when separated. Higher the genetic variability, faster is the rate of species evolution and adaption to different environments resulting in rapid development of resistance to insecticides or vice-versa.

Heckel et al. (1995) also used 117 RAPD primers to distinguish between resistance and susceptible strains of DBM and observed that 75 primers produced one or more bands that were present in either of the strains. Williams et al. (1990) reported that RAPD markers are more useful in discriminating populations and also for creating linkage maps locating disease resistance genes.In the present study, RAPD primers produced scorable bands (ABA-02, ABA-04 and ABA-12) and these strain specific bands which could discriminate between insecticide and susceptible populations. These primers can be used as genetic markers for linkage map analysis of DBM.

\section{Conclusion}

DNA from treated survivals of the acephate treated and control population of P.xylostella using RAPD primers concluded that ABA-04 primer in Andhra Pradesh population yielded specific allele for resistance against acephate. In Delhi population, ABA-12 primer produced specific amplicon against acephate and Cry $2 \mathrm{Ab}$ which is responsible for resistance.

\section{ACKNOWLEDGEMENTS}

The authors thank Dr. K. R. Kranthi, Director CICR and Dr. Sandhya Kranthi, Principal Scientist and Head, Division of Crop Protection, CICR, for their encouragement and full fledged unconditional support for providing the laboratory and material support during the molecular work.

\section{REFERENCES}

Belaj, A. Satovic, Z.G. Cipriani, G.L. Baldoni, R. Testolin,
R., Rallo, L. and Trujillo, I. (2003). Comparative study of the discriminating capacity of RAPD, AFLP and SSR markers and of their effectiveness in establishing genetic relationship in olive. Theoretical and Applied Genetics, 107: 736-744.

CIE, (1967). Distribution maps of Pests, Map No.32 (Revised), Commonwealth Institute of Entomology, London, UK.

Fakruddin, B.S.H. Prakash, K. Krishnareddy, B. Vijaykumar, P.R. Badari Prasad. Patil, B. V. and Kuruvinashetti, S. ( 2004). Genetic variation of cotton bollworm, Helicoverpa armigera (Hübner) of South Indian cotton ecosystem using RAPD markers. Current Science, $87: 12$.

Ferré, J. and Van Rie, J. (2002). Biochemistry and genetics of insect resistance to Bacillus thuringiensis. Annual Review of Entomology 47: 501-533.

Heckel, D.G., Gahan, C.J. Tabashnik, B.E. and Jhonson, M. W. (1995). Randomly Amplified Polymorphic DNA difference between strains of Diamondback moth (Lepidoptera:Plutellidae) susceptible or resistance to Bacillus thuringiensis. Annals of Entomological Society of America, 88: 531-537.

Krumm, J.T. Hunt, T.E. Skoda, S.R. Hein, G.L. Lee, D.J. Clark, P.L. Foster, J.E. (2008). Genetic variability of the european corn borer, Ostrinia nubilalis, suggests gene flow between populations in the Midwestern United States. Journal ofInsect Science, 8:1-12.

Miller, S.A. Dykes, D.D. and Polesky, H.F. (1988). A simple salting out procedure for extracting DNA from human nucleated cells. Nucleic Acids Research, 16(3): 1215.

Silva, S.C. Lemos, M.V.F. and Ayala Osuna, J.T. (2000). RAPD marker use for improving resistance to Helicoverpa zea in corn. Maydica, 45:289-294.

Sivapragasam, A., Loke, W.H. Hussan, A.K. and Lim, G.S. (1996). The management of diamondback moth and other crucifer pests. Proceedings of the third international workshop, Kualalampur, Malaysia, Pp.353.

Tang, Q.B. Jiang, J.W. Yan, Y.H, Loon, J.J.A. and Wang, C.Z. (2006). Genetic analysis of larval host-plant preference in two sibling species of Helicoverpa. Entomologia Experimentalis et Applicata, 118: 221- 228.

Tay, W.T. Behere, G.T. Heckel, D. G. Lee, S.F. and Batterham, P. (2008). Exonprimed intron-crossing (EPIC) PCR markers of Helicoverpa armigera (Lepidoptera: Noctuidae). Bulletin of Entomological Research, 98: 509-518.

Williams, J.G.K. Kubelik, A.R. Lirak, K.J. Refalsi, J.A. and Tingey, S.V. (1990). DNA Polymorphisms amplified by arbitrary primers are useful as genetic marker. Nucleic acids Research, 18: 6531-6535.

Zhou, X. Factor, O. Applebaum, S.W. and Coll, M. (2000). Population structure of the pestiferous moth Helicoverpa armigera in the Eastern Mediterranean using RAPD analysis. Heredity, 85: 251-256 